\title{
The Enlightenment to the Industry Cooperation Development of the Vocational Education in Mainland China, Experience from Taiwan
}

\author{
Pingting Huang ${ }^{1, a}$, Chun Fan ${ }^{2}$ \\ ${ }^{1}$ Guangdong industry technical college, Guangzhou, China. \\ ${ }^{2}$ Guangzhou University of Chinese Medicine, Guangzhou, China. \\ a156691826@qq.com
}

Keywords: Taiwan; Industry Cooperation Development; Technical and vocational education; Mainland China.

\begin{abstract}
In recent years, Taiwan's industry-university cooperation in technical and vocational education has developed rapidly. The government departments to establish a system of cooperation window and the direction and outcome of the development of university-industry collaboration led by the government.All these have formed a complete system of industry-university collaboration. Industry-university cooperation by strengthening legislation, diversify sources of teachers is to establish a basis for a wide range of industry-university cooperation mechanisms. These are technical and vocational education in Taiwan University-Industry Cooperation and development implications for mainland China.
\end{abstract}

\section{Introduction}

Technical and Vocational Education in Taiwan stands for technical and vocational education system in the process of development gradually improve. In the past, higher technical and vocational education is equivalent to technical college. Now in Taiwan the higher vocational education is the combination of science and technology universities.Technical and vocational education in Taiwan have a very clear position. Through school-enterprise cooperation, combining learning with theory and practice the concept of vocational education to enhance students' basic skills training and professional skills training.

Industry Cooperation Development is an education model which schools and enterprises to participate in personnel training. In recent years, Taiwan's goverment attach great importance to industry-university cooperation.So students trained are better able to be used for the community.These can provide a lot of valuable experience in the mainland areas of vocational education.Through a comparative analysis of successful practices of Taiwan Technical and Vocational Education Industry Cooperation Development Model,so as to provide reference for the development of industry-university cooperation Mainland higher vocational education.

\section{Industry Cooperation Development status quo of Taiwan and its importance of technical and vocational education}

Industry Cooperation in Higher Education in today is increasingly fiery.First is because the university get rid of "otherworldly" image for the sake of teaching and research in line with social expectations.Secondly,the enterprise to seek a breakthrough technological innovation, develop new methods.Third, because now more emphasis on students acquire practical knowledge and skills in the workplace so can understand the workplace earlier demand.Thus, Industry-University Cooperation is the government and academia's hot topic.Some of the University-Industry cooperation center was promoted to the first stage unit.Some universities set their own indicators to assess th industry-university performance.Simultaneously,the promotion of industry-academia results into the teacher's grade promotion, institutes budget, reward systems.There are even provisions university teachers at least annually to pick an industry-university cooperation as an essential way of assessment and promotion.The reason is that in the past many universities only concerned papers of SCI points, 
school teachers engaged in scientific research so wrapped up in this case is easy to overlook practical talents to develop.Now teacher grade promotion system was reformed.Now the teacher's assessment is no longer rely solely on the number of papers and quality level,Teacher assessment requires diversification,so teachers university-industry cooperation is a necessary requirement for promotion of its level. In this case, Industry Cooperation in Taiwan technical and vocational education has become an extremely important task, it's related to the survival and development of the school.

\section{The characteristics of technical and vocational education university-industry cooperation and development in Taiwan and its reference}

To help the academic community achievements, while improving product development and improvement capabilities across all industries, Taiwan's Ministry of Economic Affairs, Ministry of Education, National Science Council, are actively promoting the industry-university cooperation system. Ministry of Economic Affairs and innovative incubation center, is mainly responsible for nurturing innovation for SMEs; The Ministry of Education has Regional Industrial Cooperation Center, is responsible for technical and vocational colleges of technology, innovation and R \& D.NSC will be technology transfer center, is mainly responsible for the management of patents and technology transfer of research and development. Vocational institutions through the establishment of Innovation Incubation Center, Regional Industrial Cooperation Center and technology transfer centers to assist local development of local economy and promote industry-university cooperation and development[1]. This paper briefly analyzes the Taiwan technical and vocational education industry cooperation and development characteristics of successful practices, to talk about the enlightenment to mainland China.

Establish a system to promote industry-university cooperation. To promote industryacademia cooperation in technical and vocational education, Taiwan's government establish various forms of industrial cooperation center, which is composed of cross-sectorial, multi-joint ventures, and full participation of all teachers and students.Government, enterprise, experts compose of a committee in the year 2001 called industry-university cooperation guidance committee in order to promote and form associated policy, strategy and operation which is the highest decision-making institution.By means of the committee, Taiwan established 6 industry-university cooperation center which located on northern, central and southern area aims at combining of vocational college and research center to strengthen vocational college research ability, to deeper technical research achievement and promote development of technical application. At the end of 2006, 40 technic research centers were elected through evaluation to be established.[2]Many vocational school established creative centers which are similar to industry-university cooperation office. In the year of 2007, economic apartment set industry-university cooperation promoting office to gather and apply associated resource to cooperation.

Government funds support lead direction and achievement of industry-university cooperation. As main funds resource, government adopt policy for industry-university cooperation assistance. University and vocational college are involved in industry-university cooperation, which apply government, college, enterprise to effective act together. In order to encourage enterprise participation, government adopt special assistance policy to help enterprise, for example reduce tax or deliver subsidy.

Industry-university cooperation vocational education and training help to solve technical problem. In order to train more suitable students who are able to adapt to enterprise, in addition, enterprise staffs also learn new knowledge in school.Taiwan adopt industry-university interaction mode to operate the problem. There are 3 modes that vocational school college and enterprise cooperation, 3-year vocation education and 2-year pre-bachelor, 3-year vocation education,2-year pre-bachelor,2-year technical education,3-year vocational education and 4-year technical education or 2-year vocational education and 5-year technical education, which brings more elastically educational system. And this specialize in industry-university cooperation providing teacher students practice base. In addition, enterprise arrange professions to take part in education activity and course 
plan. Regards of the course, enterprise focus on practical ability formation and train students to formal staffs.

\section{Inspiration of industry-university cooperation specialty in Taiwan}

Taiwan absorb western modern idea of education which focus on students' industry-university cooperation personnel training and teaching quality. Industry-university cooperation improves competitive power at the same time, experience of industry-university cooperation education development obtains much positive affect to vocational education mainland China.

Improve laws in industry-university cooperation, value parts of responsibility, right and benefit. As always, Taiwan value law adaptation to promote vocational education development. There are associated law like law of pre-bachelor school, law and plan of industry-university cooperation, law of vocational training, law of enhancing education and high-level technical staffs and law of vocational training.[3]These law clearly stated about request and administration principals between government, schools, service apartment, enterprise, academic research center.On mainland China, there's corresponding law, like education law, vocation law, however laws for industry-university cooperation only maintain for some principal rules, which is lacking in specific law and operation detail that lead to difficult operation. On the other hand, mainland China tend to administrate more than legal management which lead to loose management, however, rules are not humanized enough that decision originally made by market and schools is usually affected by inflexible rules.

So learning from Taiwan industry-university cooperation, improve industry-university cooperation laws and principals to obtain vocational education to whole countries economic developing plan, which is able to insure industry-university cooperation mechanism.

Course design should be considered for student's vocational development. Taiwan vocational education courses are designed by school and enterprise, considering both demand of vocational work and school teaching, which mainly form practical vocation ability. Course structure include basic course and humanistic literacy which occupy quarter of whole credit.Professionals course include professional basic course and professional course, which is the main part of whole course. Development course mainly reflect on professional development occupied $20 \%$ of whole credit;Besides,career plan course is also included occupied 1\%.Combination of acknowledge course and professional course aims at more training skillful and qualified staffs[4].So far, vocational education in industry-university cooperation on mainland China targets at different demand, however, enterprise never get involved, thus students are not practical enough to satisfy enterprises and apply their knowledge to their work. Taiwan technical course design attracts enterprise participations which aim education course to personnel vocation. In addition, we need to change labors mind that we should take care both vocation promotion, creativity and operation ability.

Enhancing various teacher's quality formation. Taiwan technical college tend to introduce professionals to be the president of college or major director, while enterprise tends to introduce new technique to school teaching area.At the same time, college and enterprise establish favorable cooperation which provide teacher opportunity to know more newly research and practical achievement of enterprise. Regards of Taiwan's related experience, mainland China should value industry-university cooperation professionals' quality, which is the key part of industry-university cooperation education mode. This is the demand of sustainable vocational development and college adjustment and construction[5].

So far we are able to strengthen our teacher's quality in these ways:Improve practical and theory teacher formation, select well-firm staff to be teacher at school which is able to create abundant and practical class which is more similar to society.Secondly,schools demand teacher's enterprise working experience to be promoting standards. Third, provide positive condition that let teacher have more opportunity go further short term study, learn form overseas vocational situation which is keep up with international pace.

Experience of industry-university cooperation in different countries reveals that industry structure relates to educational structure and Taiwan vocational education development pace is closely 
corresponding to its industrial structure. What's more, Taiwan vocational education always adjust to suitable mode to adapt to Taiwan economic and industry development. Taiwan and mainland China share similar cultural background and similar education polity. In the aspect of industry-university cooperation, Taiwan and mainland share the same problems.

Regards of Taiwan vocational education development, we seriously consider industry-university cooperation and its future direction and development problem to enhance our vocational education competitive power.

\section{References}

[1] Lin Hui-liang, Enhancing the Cooperation of Industry and School to Upgrade the Quality of Technical and Vocational education, Vocational and Technical education(Education Science)2003, (4):31-35.

[2] Wang Lifan,The Situation of Technical and Vocational Education in Taiwan Area Industry Cooperation,World Education Information,2010( 2).

[3] Lin Ruohong,Inspiration to Mainland's Higher Vocational Education by Taiwan's Technical\& Vocational Education,Journal of Xi'an Aerotechnical College,,2009,(6):35-38.

[4] Chen Suoqing, He Yuhong, The Enlightenment of Higher Vocational Education in Taiwan to the mainland China, Education and Vocation,2011,(14):74-76.

[5] Wang Yuanyuan,Comparative Study on the Cooperative Model,University Technology of China,2010,(12):17-19. 